\title{
LA ANTROPOLOGÍA FILOSÓFICA COMO ONTOGENEALOGÍA
}

\author{
la antropología nace como una nueva forma de la antropodicea. En \\ ella comienza "el" hombre a tomarse a si mismo de manera empírica y \\ a investigar su forma de ser inspirado en su "propia" revelación. \\ Peter Sloterdijk \\ Extrañamiento del mundo
}

Los avatares antropológicos han intentado eludir un espinoso tema que tiene que ver con las condiciones de emergencia del hombre; lo que se suele decir en antropología filosófica pasa por ser una descripción de lo ya dado que deja fuera de la reflexión aquello que hace posible la aparición de los fenómenos. A pesar de ese circular modo de observar la cuestión del hombre, la investigación antropológica, quiéralo o no, se encuentra con el problema de la emergencia del hombre; este salta a la luz como un obstáculo, como un callejón sin salida. No en vano, las investigaciones tienden a cerrarse y de esta manera construyen conceptos en los que el problema de la emergencia del hombre aparece como una regresión infinita carente de sentido. El problema de la emergencia (entstehung) queda cerrado; para los antropólogos, describir qué es el hombre basta.

Iniciar aquí una investigación sobre las condiciones de posibilidad y de emergencia del fenómeno humano exige problematizar el asunto, revivirlo y traerlo al debate filosófico, para evidenciar que el tema del hombre necesita de una profunda reflexión. Lo que se intenta, de aquí en adelante, es retornar hacia los inicios, ir al comienzo, para mirar de qué modos se trazan las líneas que nos conectan con el pasado, que nos unen con nuestro ya-sido. Una labor que, para Sloterdijk, no puede estar en manos de una antropología, a menos que esta decida transformase, volverse filosófica. 
Se busca trazar un camino que nos lleve hacia la primera página de lo que somos, donde la insistencia en el problema del hombre se convierte en el eje de un pensar intempestivo, un pensar que mira las emergencias y las urgencias de lo que somos hoy. Nuestra lectura del problema del origen tiene que ver con una propuesta que no es ni de carácter regresivo, ni identitario. Se trazará entonces una serie de líneas que teja una trama argumental suficiente para construir una tesis que ofrezca un vistazo panorámico de la obra de Sloterdijk en torno al problema del hombre.

El primer hilo va de Sloterdijk a Scheler y Gehlen; tejerlo exige abordar un presupuesto inicial: la transfiguración de la antropología filosófica en un estudio ontogenealógico del fenómeno humano. Mutación que solo deviene posible cuando lo que se dice acerca del hombre se halla ordenado bajo la vestimenta de una "crítica de la razón histórica"1. La antropología filosófica es aquí un pretexto que conduce a la pregunta sobre la emergencia del hombre. Muchos de los intentos por responder qué es el hombre adolecen de una sólida respuesta sobre el comienzo de este, sus lugares son comunes y obvios.

Hasta aquí la esencia del hombre reside en su diferencia con el animal: somos hombres en tanto que superamos nuestros instintos animales; diferencia específica como negación de la animalidad, la razón como el acto diferenciador-negador que permite que el hombre se garantice a sí mismo como un no-animal. El origen de lo que somos pasa por la consolidación de la diferencia específica (razón) como armazón que ha ganado su valor a través de un ejercicio histórico que pocas veces ha reflexionado sobre la cuestión del comienzo. Todo desarrollo conceptual de la antropología se sienta en el escaparate del hombre en tanto que animal racional. Pero, ¿qué pasa cuando empiezan a tambalear los suelos, cuando los fundamentos se labran resbalosos y las estructuras trascendentes pierden sentido? Es ahí donde el comenzar debe entenderse como un acto de creación singular, como un ejercicio histórico que intenta reconstruir poéticamente lo ya sido y lo ya comenzado.

El retorno a la tradición de la antropología filosófica de Gehlen es la evidencia de un lazo con el pasado, de un comenzar desde lo ya-sido. Sloterdijk retomará dos tesis

\footnotetext{
El proyecto de una "crítica de la razón histórica" es planteado por Sloterdijk en Venir al mundo, venir al lenguaje, texto en el que expone una fuerte desestructuración del problema del comenzar. La razón histórica, argumenta Sloterdijk, no puede verse ordenada por un imperativo de carácter totalmente progresista o totalmente regresivo; por el contrario, siempre debe ordenarse desde el presente que decide responder a la cuestión "cómo he llegado a ser lo que soy". La investigación por el presente, entonces, necesita de una profunda reflexión por el comienzo que continúa, por la historia como devenir que estructura aquello que hoy somos.
} 
presentes en la obra de este sociólogo alemán que resultarán vitales para el desarrollo de su proyecto que, tempranamente, puede ser definido como una fenomenología del habitar, del ser-en-el-mundo. Los tres tomos de Esferas son en realidad una antropodicea (Sloterdijk, 2003, p. 39), un relato de los comienzos, del génesis, de cómo el hombre deja de ser una estatua arcillosa para devenir un gemelo insuflado (Sloterdijk, 2003, pp. 40-42). Las marcas sobre la emergencia del hombre son exploradas en un tema olvidado en la filosofía: el espacio. Las respuestas al comienzo del hombre son una especie de cartografía de los espacios anímicos, de los modos de habitabilidad, en los que la ontología se estructura como un saber sobre el comienzo. Preguntarse por la génesis de lo humano y desde allí hacer el intento de reinventar su historia es la consolidación de una crítica de la razón histórica; el relato "antropodiceaco" es un salto ontogenealógico, es decir, un modo de contar la historia intempestiva de nuestro devenir, de lo que hoy somos. La genealogía como ontología, el origen como emergencia, la emergencia como urgencia del presente. Al tránsito de las reflexiones esencialistas sobre el hombre, hacia la relación de lo anímico y espacial como devenir histórico es a lo que llamaremos "salto ontogenealógico".

Para efectos metodológicos, el capítulo se dividirá en tres sesiones. En la primera se explora la relación de Sloterdijk con Scheler y el hundimiento de las preguntas antropológicas en cuestiones profundas que acercan la reflexión hacia el tema del origen. En la segunda parte se verán las generalidades de la antropología filosófica de Gehlen y cómo sus tesis sobre el animal deficitario (mängelwesen) empujan a la cuestión inquietante de la antropogénesis. En un tercer momento veremos cómo la antropología filosófica deviene ontogenealogía o genealogía de lo humano en la obra de Sloterdijk, argumentando que el proyecto de una poética del comenzar es una activación metafórica de la historia critica que Nietzsche desarrolló en su obra. 


\section{SCHELER Y SLOTERDIJK: ANTROPOLOGÍA FILOSÓFICA Y CIENCIA DEL HALLAZGO}

En al menos dos puntos cruciales se tocan las obras de estos dos pensadores alemanes: por un lado, en la explícita atención a la configuración existencial del hombre; por otro lado, en el abordaje de cómo el hombre deviene para sí mismo. Scheler fue uno de esos agudos críticos a comienzos del siglo XX, para quien las devastadoras consecuencias de la Primera Guerra Mundial, la caída de algunos Estados totalitarios y la acelerada tecnificación dejaban de ser hechos aislados, para convertirse en acontecimientos que marcaban una profunda crisis en la humanidad europea. Por otra parte, las denominadas ciencias humanas recibían una dura estocada por parte del positivismo y se veían barruntadas por un cientificismo tecnicista que confinaba la reflexión filosófica a un lugar oscuro. Con Scheler se podría decir que todos estos acontecimientos iban a parar en un mismo lugar: la crisis e incomprensión del concepto de hombre.

La antropología filosófica de Scheler tiene como propósito resolver la cuestión de la esencia del hombre mediante una reconstrucción de su estructura desligada de los cánones siempre preconcebidos: el hombre como criatura de Dios, como animal racional y como cúspide de la evolución natural. Para Scheler estas respuestas pasaban de ser insuficientes a ser verdaderos problemas de comprensión de lo antropológico, no solo por su carácter apriorístico, sino también por su nivel de alcance parcial. Detenerse en la cuestión antropológica necesitaba de una meditación global del fenómeno humano y de una atrevida estructuración del concepto desde sus raíces. Scheler comprendía muy bien que cada definición canónica resultaba veraz si se entendía al hombre como un ser con dimensiones aisladas, como un fenómeno particular y solitario en la marcha histórica. Quien decidiese confrontar estas dimensiones y articular sus posibles respuestas solo encontraría el fracaso de estas como respuestas antropológicas y la contrariedad expresa de una crisis acerca de la cuestión del hombre mismo.

El puesto del hombre en el cosmos (1929) es el desenmascaramiento de los prejuicios como limitantes de la expresión del hombre y sus dimensiones. Además de ello, este texto, que resulta programático, anuncia lo que desde entonces se llamará "antropología 
filosófica”. La primera parte del texto se encarga de examinar cuáles son las razones que hacen parciales a las respuestas canónicas. Cuando uno se encuentra con la cuestión ¿qué es el hombre?, topa con tres "círculos de ideas" que intentan ofrecer una respuesta: el círculo judeo-cristiano, el círculo logocéntrico y el círculo científico-genético (psicogenético). A los dos primeros los podemos llamar "círculos de afirmación diferenciante", mientras que el tercero puede ser llamado "círculo de negación diferenciante"; las antropologías teológicas, filosóficas y científicas responden desde una visión del mundo recortada, en la que cada disciplina cuenta con una metodología restringida. Los primeros círculos de ideas, de afirmación diferenciante, realizan el concepto de hombre desde lo exterior, son afirmativos en tanto que se dicen ciertos en relación con "algo" que no son ellos mismos (Scheler, 2000, pp. 87 y ss.).

Así, en la antropología teológica el hombre es tal gracias a su diferencia de grado con Dios y en la filosófica gracias a su diferencia de grado con el animal; ambas, en todo caso, guardan una estrecha relación en su modo de proceder, en el que la especificidad del grado conduce al cierre del círculo y a la respuesta a todo lo que tiene que ver con el hombre. El último círculo de ideas responde, por el contrario, con una diferencia específica que niega; el hombre no es animal gracias a su aparataje biológico que ha evolucionado con el paso del tiempo. Así pues, en tanto que este círculo de ideas pretende examinar minuciosamente la diferencia en pro de una negación que sublima la naturaleza y desdeña lo que es inferior, se acentúa cierta discrepancia que tiene como resultado una identificación del hombre y la idea de superioridad sobre la naturaleza. No es extraño que esta indicación resulte ser ampliamente valedera entre quienes comprenden que el saber es poder y que las relaciones que el hombre entabla con su mundo solo pasan por ser meramente instrumentales y objetuales.

A pesar de la extensa tradición y de la suficiente cantidad de afirmaciones que hacen a estos círculos de ideas verídicos, Scheler muestra una carencia de parte de esas maneras de comprender al hombre y alega por la posibilidad de construir un concepto esencial del hombre, que no separe cada una de sus dimensiones. De esa manera, la antropología filosófica de Scheler parte de la subordinación del concepto sistémico-natural de hombre por un concepto esencial. Un concepto que ha de responder de manera total a lo que es el hombre y consecuentemente no podrá estructurarse desde ningún sesgo parcial ni verse constreñido por algún prejuicio. ¿A qué deberá responder entonces ese concepto esencial?, a si es legítimo y válido considerar que el hombre puede arrogarse el derecho de decir que ocupa un lugar singular en el mundo. Un concepto esencial del hombre intenta fundamentar ese privilegio del que goza el homínido gracias a su 
esencia radical. Para poder sostener esa visión será necesario construir una antropología filosófica que afirme al hombre como el individuo de la diferencia en todo sentido.

Para Scheler es claro que el hombre es un ser que recompone su esencia a partir de la mejora de sus facultades para modificar la relación con su entorno; por lo tanto, ser hombre no significa carecer de algo, sino que el estatuto de hombre se obtiene gracias a la mejora de las facultades vitales. Así pues, el hombre comparte con el resto de seres de la naturaleza el estadio de la vida en el que se desarrolla el impulso afectivo, el instinto, la memoria asociativa y la inteligencia (Scheler, 2000, pp. 42-65). En este nivel de la vida no existiría una diferencia con el animal, ni de tipo genérico ni facultativo, pues el hecho de que cada ser pueda poseer una o más de esas facultades afirma cierta semejanza en el nivel orgánico, lo cual significa que la diferencia hombre-animal no puede residir en el estadio de la vida. El hecho de que el hombre sea una parte más del cosmos no indica que desde siempre haya ocupado un puesto singular en este. Incluso podría decirse que el puesto singular del hombre es producto de un tránsito histórico en el que cada una de estas facultades, del estadio de la vida, ha mejorado las relaciones con su entorno.

Una de las batallas conceptuales más fuertes a la que Scheler se enfrenta tiene que ver con la diferencia de grado entre la inteligencia animal y la inteligencia humana, como si toda la batalla de la antropología filosófica se diera en el terreno que justifica la diferencia específica. Scheler no llama racionalidad al estadio de esta diferencia, sino espíritu. Una cierta vocación de corte teológico es evidente en la reflexión filosófica de Scheler, pues es gracias al puesto metafísico del hombre que este resulta "diferente" con respecto a los demás seres vivos. "Lo único que hace que el hombre sea 'bombre' no es un nuevo estadio vital, ni todavía menos uno de los estadios de manifestación de la vida, la psique, sino un principio opuesto a toda vida en general, incluida la vida del hombre: una realidad esencial verdaderamente distinta, del todo irreductible a la evolución natural de la vida" (Scheler, 2000, p. 66).

La contraposición entre espíritu y vida es entonces el lugar donde se desarrolla la antropología filosófica de Scheler y en el cual se estructura su concepto esencial del hombre. Podemos sostener que tal contraposición se debe a la legitimación del saber filosófico como saber total que intenta estar por encima del sesgo de legitimidad de la biología de los años veinte, pues una teoría sobre el hombre no puede descansar en una diferencia de nivel entre los modos de operación de la inteligencia en la naturaleza. Por ello, Scheler define la inteligencia "como comprensión de una situación (conforme a la naturaleza contingente) en virtud de un sistema de referencia cuyos fundamentos están dados en parte en la experiencia y en parte son completados por anticipación en la 
representación" (Scheler, 2000, p. 60). Así que todo rasgo inteligente tiene que ver con cierta capacidad de anticipación del fenómeno, con la previsibilidad de lo que acontece con cierta regularidad en la naturaleza. Scheler admite de esa manera la profunda discusión que existe en torno a si un animal es o no es inteligente, haciendo de la inteligencia solo un estadio más de la vida psíquica del individuo que no puede arrojarle una diferencia fundamental.

Scheler señala que en los animales la inteligencia funciona gracias a cierta predisposición a una finalidad complaciente en la que se usan determinados medios o herramientas. Así, cuando el mono logra alcanzar una banana con la sábana con la que se arropa diariamente, se comprende que el "uso" de su aparato orgánico no responde a un mero y simple impulso afectivo, sino que necesita de la ordenación de cierta información y de la organización de esta en su entorno en virtud de una finalidad, en este caso alcanzar la banana.

El animal no es un mecanismo de impulsos, como tampoco es una máquina instintiva y un mecanismo de asociaciones y reflejos [...] El animal es capaz de intervenir espontáneamente en esta constelación de impulsos y abstenerse, hasta cierto punto, de gratificaciones inmediatas para obtener gratificaciones mayores, aunque más lejanas en el tiempo y solo accesibles mediante rodeos (Scheler, 2000, p. 64).

La diferencia hombre-animal radica, entonces, en un escenario distinto al de la inteligencia ordenada y la mera repetición de actos por impulso: "la esencia del hombre y lo que puede llamarse su puesto singular está por encima de lo que se denomina inteligencia y facultad de elegir, y tampoco se captaría imaginando un acrecentamiento cuantitativo, ni siquiera infinito de estas dos facultades" (Scheler, 2000, p. 66). Lo verdaderamente diferente reside en un escenario completamente distinto al de la vida orgánica y su conjunto, escenario que Scheler denomina "espíritu”. ¿Qué implicaciones antropológicas tiene el hecho de que el espíritu sea el escenario de la diferencia entre el hombre y el animal? Si algo es importante en el desarrollo que Scheler inicia es la posibilidad de desmentir los aprioris de talante humanista que dan por sentada esa superioridad por parte del hombre sobre el resto de la naturaleza. Por ello es indispensable la consideración del hombre como una parte más de la naturaleza, del mundo biopsíquico, al que corresponden tanto la facultad de la inteligencia como el instinto y los impulsos afectivos. El hombre llega a ser tal solo mediante la ideación y la efectiva realización 
de esa ideación, proceso que únicamente es posible en tanto que exista una especie de alejamiento del mundo orgánico y un despliegue de las facultades del hombre en lo espiritual: "la determinación fundamental de un ser espiritual, sea cual sea su constitución psicológica, es su desvinculación existencial de lo orgánico, su libertad, su independencia, o la del centro de su existencia, respecto del cerco, de la presión, de la dependencia de lo orgánico, de la 'vida' y de todo lo que pertenece a la vida, y también, por lo tanto, de su propia 'inteligencia' impulsiva” (Scheler, 2000, p. 67).

El hombre se convierte para Scheler en el único viviente capaz de saberse poseedor de un puesto singular cuyas características ya no están escritas en un plano de orden biológico, sino que se trazan en la estructura de un plano ontológico, en el que adopta una nueva actitud hacia el mundo. Esa nueva actitud tiene que ver con la posibilidad, que solo posee el hombre, de preguntarse por el lugar que ocupa en el cosmos, por la legitimidad de ese lugar y por las razones históricas que acompañan ese desarrollo. E1 lugar que el hombre ocupa en la historia no es el producto de un azar contingente o de una actuación de la providencia divina, pues para Scheler está claro que la capacidad de desarraigo de la tradición es el modo esencial que tiene el hombre de habitar el mundo, pues "todo verdadero desarrollo humano descansa esencialmente en una creciente desestructuración de la tradición” (Scheler, 2000, p. 57). El ser del hombre pasa entonces por el distanciamiento del ámbito de lo orgánico y su instalación en lo espiritual como algo objetivo:

Espíritu es, pues, objetividad, posibilidad de ser determinado por el ser-así de las cosas mismas. Solo "tiene" espíritu el ser vivo capaz de alcanzar la objetividad plena. O más exactamente: solo es "portador" de espíritu el ser cuya relación fundamental con la realidad fuera de él y en él, a diferencia del animal y de su inteligencia, ha invertido su dinámica (Scheler, 2000, p. 68).

La inversión de esa dinámica consiste en la posibilidad de disponer del mundo como objeto de conocimiento para-sí y como conocimiento de sí mismo, mediante el encausamiento de los impulsos de la vitalidad para una resistencia del ser-sí-mismo. La antropología filosófica permite preguntarse por la peculiaridad inmanente del espíritu, en tanto que alejamiento de lo orgánico-vital. Ese alejamiento es el resultado de una resistencia a los impulsos afectivos (vitales) que son coconstitutivos del hombre como habitante del cosmos. Sin embargo, "un ser 'espiritual' ya no está, pues, ligado al impulso y al medio, es un ser 'libre respecto del medio' y -así queremos llamarlo nosotros- 'abierto 
al mundo': este ser tiene 'mundo"' (Scheler, 2000, p. 67). Esa libertad se obtiene gracias a los procesos de resistencia de la vitalidad del mundo, lo cual significa que el espíritu en tanto que objetividad y alejamiento se convierte en el escenario en el que se alcanza plenamente la esencia del hombre. Una antropología filosófica, como el mismo Scheler señala, intentará evidenciar de qué manera funcionan el resto de estructuras propias del hombre en relación con su constitución fundamental, es decir, en relación con su mundo espiritual. Para Scheler el mundo termina siendo una esfera dada de antemano.

Justo en este punto es donde se unen y se separan Sloterdijk y Scheler, pese a que los aspectos más recurrentes en la obra del pensador de Karlsruhe resuenan con esta última parte de la antropología scheleriana. Sloterdijk es heredero de un camino pragmático y desesencializador que resuena a mayor escala con el sociólogo alemán Arnold Gehlen. Pese a ello, es posible encontrar una reiterada problematización de la antropología filosófica como saber que pregunta por tres elementos cruciales: la condición del sí-mismo y su apertura al mundo (Scheler, Gehlen, Sloterdijk), por la particularidad de su lugar singular (Scheler y Sloterdijk) y la peculiaridad de su forma de acceder a esa pregunta como un evento transformador (Sloterdijk). Podremos afirmar que existe una caja resonante entre estos tres autores, en los que la pregunta por el hombre se convierte en una cuestión que puede transformar los cimientos de la existencia de cada individuo particular'.

Para argumentar esto disponemos de un texto de Sloterdijk que resuena críticamente con la última parte de El puesto del hombre en el cosmos. Existe un enorme parecido entre dos apartes textuales que a su vez tiene intenciones dispares y que para nosotros constituye una renovación crítica de la pregunta antropológica. El texto de Scheler es el siguiente:

Una vez que el hombre se ha colocado fuera de la naturaleza y se ha convertido en su objeto - esto pertenece a su esencia, es el acto mismo de hominización-, ha de volverse en torno suyo, estremeciéndose, por decirlo así, y preguntar: ¿Dónde estoy yo mismo? ¿Cuál es mi lugar? Propiamente, él ya no puede decir: soy una parte del mundo, estoy cercado por el mundo, pues el ser actual de su espíritu $\mathrm{y}$ de su persona es incluso superior a las formas de ser de este mundo espacial y temporal (Scheler, 2000, p. 123).

2 La resonancia con ese proyecto será evidenciada con la lectura total del primer capítulo. 
El anterior texto es la puerta de entrada al discurso de Scheler acerca de la preeminencia del puesto metafísico del hombre, desde el cual se podría afirmar que una definición del hombre scheleriano sería la de animal metaphysicus. El puesto singular del hombre para Scheler tiene que ver con la posibilidad que guarda de verse a sí mismo como transcendente y alejado de la estancia mundana. Es un imperativo diferencial que le garantiza el acceso al mundo desde una superioridad ontológica ${ }^{3}$. Ese tipo de superioridad es para Scheler la indicación de una relación metafísica entre la estancia del hombre en el mundo y su fundamento, que sirve como justificación de esa contingencia radical a la que el hombre es sometido desde su venida al mundo. Así pues, para Scheler es necesario que el hombre pueda objetivar su mirada, justificándola desde su particular puesto metafísico. Preguntarse por su lugar particular es la manifestación de una conciencia alejada del mundo que palpa esa sustancialidad de la que es partícipe.

Si para Scheler la pregunta antropológica desemboca en una inevitable contrariedad metafísica que explicita el lugar de comunión que aparta al hombre de la vida hacia el espíritu, en Sloterdijk la cuestión adquiere un carácter de orden intramundano en el que la contingencia radical y la inmanencia resultan determinantes. El texto de Sloterdijk es el siguiente:

No soy ninguna de las cosas -eso quiere decir que ya no hallo ningún amparo en lo que no es humano-; no soy, y ahora lo sé, piedra, ni planta, ni animal, ni máquina, ni espíritu, ni Dios. Con esta séxtuple negación circundo lo inquietante de todos los espacios. Quien es hombre vive en una posición que se extraña absolutamente de sí misma. A partir de ahí, no soy más que escenario de una pregunta. Mi vida es un teatro del estremecimiento de que tengo que ser algo diverso de todo aquello que goza de confort, cosa entre cosas, ser entre seres. ¿Por qué me toca a mí? (Sloterdijk, 2008, pp. 29-30).

\footnotetext{
Un dato muy curioso y quizá inexplorado es el profundo vínculo que puede existir entre esta última parte del texto de Scheler y algunas de las indicaciones de Heidegger en Carta sobre el humanismo; especialmente, se hace referencia a aquellas fuertes indicaciones del maestro de Alemania en las que alude que la esencia divina nos es incluso más cercana que la naturaleza animal. Es claro que hay que guardar las distancias entre estos dos autores, pero de fondo pueden existir profundos lazos de conexión entre uno y otro, que podrían ser explorados desde Ontología hermenéutica de la facticidad, pasando por Ser y tiempo, hasta estas últimas indicaciones de Carta sobre el humanismo.
} 
Es justamente esa especificidad que logra hacer del hombre un algo diferente de los objetos la que puede constituir su espacio de habitabilidad mundana. La pregunta antropológica para Sloterdijk es también la pregunta por el puesto singular, pero en relación con la materialidad del mundo mismo; el hombre circunda su mundo con la angustia motivante de no ser absolutamente ninguna de las cosas exteriores, pero de poder preguntarse, sin embargo, por qué le toca a él, en su singularidad, responder por su lugar. Indefectiblemente, Sloterdijk hunde la pregunta antropológica hacia un asidero en el que la propia singularidad se asombra de la peculiaridad espacial en medio del entorno mundano. No se trata, entonces, de exaltar la capacidad metafísica para generar una distancia de grado con el animal, sino de animar una problematización de por qué el hombre se atiene a un lugar especial con su venida al mundo.

De modo que al volverse en torno suyo, el hombre hunde su mirada, por decirlo así, en la nada: su mirada le descubre la posibilidad de la nada absoluta y esto le impulsa a seguir preguntado: ¿por qué hay un mundo, por qué y cómo existo "yo"? (Scheler, 2000, p. 123).

Esa misma pregunta es la que intenta ser respondida por Sloterdijk, con la diferencia de que este no lo hace desde la perspectiva metafísica de Scheler; no se trata de un teomorfismo y de la indicación de que esa justificación está dada por el puesto singular ocupado por el espíritu. Sloterdijk intentará configurar una ontología histórica de los hechos humanos que revele cómo el hombre viene al mundo y transforma su estancia mundana asumiendo su lugar particular y transformándolo cada vez que puede. Por ello, para el filósofo de Karlsruhe serán más determinantes las ideas del sociólogo alemán Arnold Gehlen, quien considera al hombre como un "ser activo" cuya naturalidad pasa por ser un mero acto de su inteligencia técnica. 


\section{La herencia de GeHLen}

Se partirá de una de las indicaciones que el mismo Gehlen ofrece en una de sus conferencias, en la cual expone algunos de sus argumentos para reconstruir una historia de la antropología filosófica. Para Gehlen, los intentos antropológicos posteriores a Kant erraron el camino y distribuyeron sus esfuerzos para construir una teoría del hombre desde ámbitos metafísicos y transcendentes. Incluso Scheler, quien intentó derrumbar algunos de los prejuicios antropológicos -como fue expresado arriba-, queda atrapado en esa visión metafísica del hombre que considera que ser humano es gozar de cierta posibilidad transcendente que dispone el mundo de manera objetual. Pese a las discrepancias que Gehlen tiene con Scheler, reconoce que fue este último quien puso sobre un nuevo camino la problematización de la cuestión del hombre:

la concepción de hombre como ser primordialmente activo, entendiéndose por acción la actividad destinada a modificar la naturaleza con fines útiles al hombre. Ésta fue mi posición, la que no dejaba de estar influida por una orientación filosófica americana llamada pragmatismo, aunque conservaba dos tesis básicas de Scheler: el punto de partida de la comparación del ser humano con el animal, y la teoría de que el hombre está abierto al mundo, esto es, su posibilidad de ser impresionado por una multiplicidad cualquiera de informaciones del mundo exterior, aun cuando sean biológicamente indiferentes o incluso perjudiciales (Gehlen, 1993, p. 32).

Cabe recordar que la pretensión de Scheler era construir una teoría sobre el hombre que sirviese como teoría total, en tanto que esgrimiera las diferencias entre las dimensiones constituyentes de lo humano; aspecto que llevó a definir al hombre como un ser espiritual que solo puede llegar a tal compromiso consigo mismo desde la resistencia a sus impulsos orgánico-vitales. La existencia humana para Scheler es una cuestión de resistencia a los impulsos vitalicios, en tanto que alejamiento de lo orgánico y desvelamiento de lo espiritual, de lo que está más allá de este mundo sensible. La concepción espiritual de Scheler es entonces la garantía de comunión entre las dimensiones 
biológica y metafísica. Gehlen proseguirá el camino de una antropología filosófica que de cuenta de la totalidad del hombre por otros caminos. Así, en El hombre, su naturaleza y su lugar en el mundo (1987) dicho autor afirma que solo podrá encontrarse algo verdaderamente humano en el momento en el que se piensen de modo unitario las dimensiones que constituyen la realidad del homínido. "Mientras no tengamos una visión total del hombre tendremos que quedarnos en la contemplación y comparación de las características individuales, y mientras nos quedemos ahí no existirá una antropología independiente, ya que no habrá un ser humano independiente" (Gehlen, 1987, p. 14). La totalización de las dimensiones humanas es la configuración de un gran relato sobre el hombre, que tiende a desbaratar los dualismos configurados por la historia del pensamiento occidental. De ese modo, la antropología filosófica no puede verse obligada a optar por lo espiritual o lo biológico, sino a procurar un esclarecimiento del fenómeno humano como unidad.

A diferencia de Scheler, Gehlen considera que en el hombre no existe una ambigüedad entre espíritu y vida, sino que ambos estadios son dimensiones del ser humano. Esto indica que la sustancialidad del hombre y su esencia no están restringidas al escenario del espíritu, sino que incluyen la transformación técnica de su entorno. Para Gehlen el hombre es un ser activo que dispone de la conciencia de su naturaleza orgánica para transformarla en virtud de su propia supervivencia. La concepción del hombre como ser activo está sustentada en dos ideas determinantes para nuestro propósito: por un lado, la consideración del hombre como un ser deficitario (mängelwesen) y, por el otro, la propuesta del hombre como un ser naturalmente cultural.

Toda acción es para Gehlen la manifestación de una inteligencia ordenada que modifica la exterioridad en virtud de un mejoramiento de las condiciones de vida: "la acción es de por sí -diría yo- un movimiento cíclico complejo que se conecta a través de las cosas del mundo exterior, y la conducta se modifica según los resultados que avisa de vuelta" (Gehlen, 1993, p. 34). Este movimiento cíclico exterioriza la deficiencia natural del equipamiento vital del hombre y articula la consolidación de un proceso de transformación de la conducta. La acción es una respuesta a la agresión del medio físico por medio de las facultades internas que el hombre posee.

Así pues, la observación de que el hombre es un ser desvalido es la primera premisa para comprender cómo es posible que la acción sea el rasgo esencial del ser humano. Gehlen afirma que el hombre 
está orgánicamente desvalido, sin armas naturales, sin órganos de ataque, defensa o huida, con sentidos de una eficacia no muy significativa; los órganos especializados de los animales superan con creces cada uno de nuestros sentidos. No está revestido de pelaje ni preparado para la intemperie, y ni siquiera muchos siglos de auto-observación le han aclarado si en verdad posee instintos, y cuáles son (Gehlen, 1993, pp. 63-64).

Es evidente que Gehlen está profundamente influenciado por la biología positivista de los años treinta en Alemania y que articula dicha argumentación con el naciente pragmatismo norteamericano. Sin embargo, no podemos ver en Gehlen a un pensador evolucionista que afirma la superioridad del hombre dentro de la escala natural; por el contrario, Gehlen considera que es el puesto desvalido del hombre el que le otorga su esencia radical. "No puede existir acción sin desvalimiento", sería una frase para describir la antropología de Gehlen.

La naturaleza humana consiste en la tragedia de haber nacido sin un equipamiento suficiente para vivir a la intemperie, por lo que el hombre se ve avocado a la transformación de su entorno para la subsistencia en lo orgánico. Sloterdijk ve en la propuesta de Gehlen la posibilidad de que la antropología filosófica pueda llegar a una definición del hombre desde sus propios medios y no en relación con una exterioridad. La tesis central que Sloterdijk tomará de Gehlen es que el hombre resulta ser un animal deficitario que deviene humano sólo a través del uso de una serie de técnicas. Esto quiere decir que el hombre no tiene a su mano la técnica, sino que es la técnica la que lo hace devenir hombre. El homínido es fundamentalmente un "ser deficitario", un animal carencial que adolece de una indumentaria natural capaz de hacerle sobrevivir en el escarpado mundo exterior: "La falta casi total de órganos cargados de instintos especializados; el mundo como esfera indefinida, infinitamente de su existencia; y la necesidad de vivir eligiendo y adoptando actitudes, o sea, de actuar, no son sino aspectos diferentes de una misma situación básica humana" (Gehlen, 1993, p. 48).

$\mathrm{Al}$ no poseer garras, alas, o dientes afilados, el hombre se torna incapaz de vivir en la naturaleza. No posee la capacidad de adaptarse al medio ambiente porque este último supera su constitución orgánica. Justo por esa deficiencia natural, el hombre se ve a sí mismo en la imperiosa necesidad de alzarse contra la naturaleza primera y convertirse en el creador de una segunda naturaleza en la cual pueda sobrevivir. La creación de esa segunda naturaleza es, al igual que en Scheler, un movimiento de distanciamiento y 
la expresión de un impulso de descarga. Este impulso es la manifestación del lenguaje como una operación de alejamiento que objetiva al mundo y que permite la creación de un mundo técnico. El desarrollo del lenguaje es el medio a través del cual el hombre se asume a sí mismo como tal y genera un interior, la elaboración de un espacio que complementa e inmuniza la carga "deficiente" de su equipamiento biológico. El lenguaje aparece entonces como un modo de inmunización y radicalización del distanciamiento entre la naturaleza y la cultura. La seguridad ontológica afirma un lugar conocido para aquel al que le resulta extraño el mundo biológico. La naturaleza primera se vuelve diferente, extraña y hostil, mientras que el nuevo mundo inmunológico deviene culturalmente de un proceso de descarga.

El hombre se convierte, de ese modo, en el ser capaz de crear un medio ambiente artificial en el cual sobrevivir. El animal humano dejó de ser un "ser natural" para devenir un "ser cultural". La técnica se convierte así en una serie de acciones estratégicas, ordenadas y coordinadas para una finalidad particular: la producción de espacios artificiales donde el hombre puede existir. De tal manera que la técnica no es el producto de abstracciones elaboradas con fines productivos, no es tampoco una mera operatividad seriada, sino que es la puesta en escena de la inteligencia como ejercicio de acción. "Desde su aparición la técnica ha acompañado al hombre, y es tan originariamente ingeniosa como él mismo [...] sería el principio de sustitución de órganos, junto al cual aparecen en adelante la descarga y la superación de órganos" (Gehlen, 1993, p. 114). La técnica no es un suplemento premeditado en la mano del hombre, sino el modo de construir un interior desde la regularidad del ejercicio. Fue necesario entrenarse, de un modo u otro, para abrigarse a la luz de una fogata, como para reunirse en una sala constitucional; los procesos de asociación y los de compensación inmunitaria fueron vitalmente procesos históricos de autodomesticación.

La serie de acciones ordenadas que diagnostica Gehlen evidencia que el hombre no es racional únicamente con el advenimiento de las altas culturas, sino que con la regularidad de la práctica puede devenir tal cual es. El hombre goza así de racionalidad gracias a un adiestramiento por medio de las técnicas. En esta perspectiva es impensable que el hombre haya devenido por gracia o por providencia; fue la manera de enfrentarse y habitar el mundo la que le empujó a darse a sí mismo una segunda naturaleza tan convincente que se volvió para él "su" naturaleza. El hombre no es entonces la cúspide de la evolución natural, sino la cúspide de su propia evolución, el resultado de la creación de un mundo artificial cuya característica fundamental es la virtualidad. "Nuestra conducta se torna cada vez más variada, pero también más virtual, simple 'capacidad'; lo 
percibido es cada vez más mera indicación de posible despliegue, al que en la mayoría de los casos ya no nos entregamos" (Gehlen, 1993, p. 68). Esta argumentación de Gehlen será determinante para Sloterdijk, quien considerará que toda la naturaleza humana vive gracias a la creación de úteros técnicos, de placentas inmunológicas.

El hombre es el único animal viviente capaz de crear un mundo a través de la técnica, de modo que la esfera cultural se convierte en "su" naturaleza y por lo tanto el lugar donde puede vivir. El ser humano

vive como ser cultural, es decir, de los productos de su actividad previsora, planificada y mancomunada, que le permite procurarse, transformando previsora y activamente, conjuntos muy diversos de condiciones naturales, técnicas y medios de vida. De ahí que pueda llamar esfera cultural a la respectiva suma de condiciones iniciales modificadas por su actividad, en las cuales solo el hombre vive y puede vivir (Gehlen, 1993, pp. 64-65).

La creación cultural es entonces producto de esa carencia orgánica esencial con la cual el hombre es arrojado en el mundo; su imprevisión y su falta de instinto son el empuje necesario para la gestación de una estructura radicalmente opuesta al agreste exterior natural. La hominización tiene que ver con un proceso de conciencia de la carencia facultativa y de creación de un sustituto ontotécnico de supervivencia. La cultura es el "medio ambiente" creado por el hombre que se convierte en su naturaleza y que anima su deficiente composición natural.

De esa manera,

al desprenderse del esquema dualista y de la metafísica, la concepción del hombre como ser activo parece útil y fructífera, pues la acción es, por una parte, actividad de un organismo -de un organismo inteligente- $y$, por otra parte, efectúa algo en el mundo, introduce un cambio, le otorga finalidad, interviene. Así se establece la vía de enlace en que finalmente se encuentran los enfoques biológico y científicocultural del hombre (Gehlen, 1993, p. 39).

Esta articulación hace que el mundo sea comprendido como una actividad inteligente, construida por el hombre gracias a su desvalimiento biológico. Así, la argumentación supone el debilitamiento de aquellas estructuras metafísicas en las que la superioridad ganada por el hombre es producto de una evolución o de un milagro divino. 
Justo en este punto es donde podemos empezar a comprender cómo la antropología filosófica en Sloterdijk intentará configurar un nuevo estadio de reflexión que no desvincula la ética y la ontología. En Sloterdijk el problema de la antropología filosófica tendrá un giro interesante al retomar los argumentos de Gehlen sobre el devenir técnico del hombre, pues mostrará que el problema central de la antropología es trazar una genealogía de lo humano o, como Nietzsche lo hubiese dicho, el problema de la antropogénesis. De aquí en adelante se equipararán ambos términos y buscaremos explicitar cómo la antropología filosófica se vuelve ontogenealogía, en la medida en que procura pensar las condiciones de emergencia del fenómeno humano, siendo el primer antecedente para esa indicación la tesis de Gehlen del hombre como un ser deficitario.

\section{LA ANTROPOLOGÍA FILOSÓFICA COMO ONTOGENEALOGÍA}

Durante el transcurso del capítulo hemos intentado señalar las razones por las cuales es posible y admisible argumentar que la reflexión de Sloterdijk asume el problema antropológico con seriedad. Así pues, hemos explorado dos vertientes del desarrollo que intentan dibujar un trazo histórico en el que este pensador alemán aparece como heredero de las reflexiones de Max Scheler y Arnold Gehlen. En ambos casos la pregunta por el hombre es una cuestión que, tarde o temprano, topa con el problema del origen del humano, y queda así indeterminado saber cuál es realmente la respuesta a ese cuestionamiento. En Scheler la pregunta por el hombre sigue indagando por la esencia como concepto "total" que demarca los límites entre lo animal y lo humano. Por el contrario, en Gehlen la pregunta por el hombre está animada por un rastreo, en parte histórico, que argumenta el concepto de hombre como una construcción cultural que ha devenido histórica y biológicamente. Ante este panorama, Sloterdijk construye una reflexión que deslinda y sumerge la pregunta antropológica en una revisión de tipo genealógico. Esto quiere decir que ya no es determinante la pregunta por el hombre que conduce a una 
construcción conceptual “total”, como pretendía Scheler, sino que la cuestión debe ser sometida a una revisión histórico-valorativa que comprenda cuáles son las condiciones de posibilidad para la emergencia de lo humano. A este profundo cambio en la cuestión antropológica lo denominamos salto ontogenealógico. Este salto se da en dos vías: por un lado, la pregunta por el hombre se vuelve una pregunta que interroga a cada sujeto particular, es decir, que cada quien debe darse una respuesta acerca de quién es y gracias a qué es así. Al igual que Scheler, la antropología hunde raíces en un suelo existencial que empuja las preguntas a cuestiones singulares. Por otro lado, el salto consiste en una regresión, en una exploración de las condiciones y de los espacios en los que fue posible la emergencia del hombre y la creación del mundo.

En Sloterdijk existe una especie de hundimiento, de inmersión de las preguntas antropológicas que consiste en trasladar la cuestión del hombre desde un ámbito estrechamente esencialista hacia un ámbito ampliamente histórico, en el que se dejan de lado las recurrentes definiciones tradicionales, para incurrir en las inexploradas condiciones de posibilidad en las que emerge lo humano. El trabajo de Sloterdijk se concentra en una exploración nómade de los espacios en los que es posible el advenimiento del hombre; lo antropológico recibe un estatuto histórico en el que se configura y responde cómo el hombre ha devenido tal. No se trata entonces de una pregunta de orden metafísico en la que se responde con un concepto unívoco, sino de una cartografía del mapa histórico que se ha trazado hasta el hombre contemporáneo. La pregunta deja de ser una cuestión extemporánea y se convierte en un desarrollo genealógico cuyo eje es ubicar la emergencia del hombre en un acontecimiento que tiene un lugar en la historia.

Así pues, existen al menos dos vías de resolución de la cuestión: aquella que arroja la investigación a un suelo existencial y una que indaga las probabilidades históricas del advenimiento del hombre desde su nacimiento como creador del mundo por medio del lenguaje. La primera de las vías se explora en el texto Extrañamiento del mundo (1993), en el que Sloterdijk propone una especie de "antropología del adviento" que consiste en explorar de qué manera los hombres vienen y salen del mundo.

En este texto, escrito a modo de ensayo, se desarrolla una perspectiva antropológica que está fundamentada en el concepto de extrañamiento: el hombre es considerado como un ser que ocupa un lugar diferente al resto de cosas del mundo; es un ser desvalido que ha sido sobrepasado por el afuera hostil de la naturaleza y que necesita asumir su extraño lugar para poder habitar el mundo. La habitabilidad del mundo depende entonces de un profundo cambio en la valoración de esa condición de extrañeza que es cooriginaria al hombre. Su existencia es efectiva mediante la transformación del 
afuera hostil en mundo susceptible para ser habitado. Así pues, durante el transcurso del libro lo que se presenta es una cantidad de relatos y de acontecimientos históricos en los que se ha dado una transformación en las valoraciones de la extrañeza como aquel lugar primigenio en el que el hombre hace efectiva su entrada al mundo. El impulso de la creación depende del ímpetu con el cual el hombre se enfrente a un mundo e intente transformar lo que le resulta extraño.

El primer espacio que el hombre habita está constituido por un afuera hostil que sobrepasa su vitalidad. La naturaleza segunda del hombre deviene gracias a una extensa capa de relatos, construida a lo largo de la historia en diferentes lugares y situaciones, con la que el hombre rompe su circunstancia primera e inaugura una instancia llamada "cultura". El ímpetu con el cual se forma la humanidad depende de la fuerza creadora que arroje la extrañeza en los hombres. De esa manera, lo antropológico pasa de ser un estudio de los hechos que afirman la existencia del hombre a ser una cartografía de esos ímpetus que forjan a los hombres y sus temperamentos. Esta cartografía de los ímpetus explora el modo en el que los hombres construyen relatos de sí mismos que los llevan y los traen al mundo:

El movimiento del venir-al-mundo es, en suma, según su modo de ser, la metamorfosis o el traslado del propio Yo desde el seno materno al seno del mundo, cuya índole inquietante consiste en ser un "continente" que, a causa de su inconmensurabilidad, más que contener a los individuos los deja caer (Sloterdijk, 2008, p. 73).

Sloterdijk demostrará que la pregunta por el hombre se convierte en un ejercicio de comprensión histórica en el que se desmantelan las verdades humanistas y se superponen una serie de relatos en los que lo humano es un proceso de autocrianza y de creación metafórica del mundo. Lo antropológico deja de estar mediado por el ímpetu de una resolución total y pasa a ser reconstruido mediante el mapeo de una serie de prácticas de hominización que han sido superpuestas en la escena de la historia.

En Extrañamiento del mundo Sloterdijk propone una vía de ensayo en la que la cuestión del hombre desborda los límites del humanismo clásico, girando hacia una vertiente que toma con seriedad la pregunta en torno a sí, y concluye que la existencia del hombre se autogestiona su propia salida. La primera vía del salto ontogenealógico, que aquí llamaremos "salto ontológico", se comprende a la luz de una de las afirmaciones de Sloterdijk: "La misma humanización solo es inteligible como la salida que el animal sin salida se procura en su huida hacia adelante. En eso, son los hombres, de la cabeza a los 
pies, criaturas de la huida hacia adelante, vástagos de la metáfora, de la metamorfosis" (Sloterdijk, 2008, p. 59). Esta variable muestra cómo la definición del hombre depende de su fuerza creadora y de su ímpetu para salir de sí mismo y atacar su indefensión desde la transformación de un afuera que se le presenta hostilmente. En este sentido, que el hombre "salte" hacia su humanidad responde a que se asume como un animal que debe transfigurar su existencia en virtud de un afuera que está enfrente. La naturaleza hostil se convierte para Sloterdijk en una de las condiciones de posibilidad para la emergencia y en el espacio determinante para la construcción del mundo humano. Asumir la pregunta por el sí mismo, como problematización del suelo existencial, significa a su vez explorar la salida que el hombre se dará y el suelo cultural al que irá perteneciendo mediante la construcción de una segunda naturaleza. Sloterdijk es aquí cercano a Gehlen, para quien el hombre construye su mundo y habita la naturaleza gracias a su capacidad para crear técnicamente una esfera cultural.

Esta primera vía del salto ontológico hace referencia a la reflexión que el hombre gesta sobre sí mismo, sobre su singularidad, es decir, a la formulación de aquellas preguntas sobre quién soy y quién he sido, que son inherentes para cualquier sujeto en algún momento de su existencia. No se trata, por supuesto, de una reflexión de tipo epistemológico que pretenda sostener un saber seguro y psicológico sobre la cuestión, sino de la puesta en escena de un ejercicio que se desborda entre lo conceptual y lo existencial. La pregunta por quién y qué he sido modifica la existencia del hombre y plantea un ejercicio de investigación que excede una definición estrechamente conceptual. La antropología tradicional se torna insuficiente en la medida que no provee un saber sobre las condiciones de emergencia de nuevas valoraciones sobre lo humano y su capacidad de extrañarse.

El salto consiste entonces en argumentar que los conceptos y las ideas de hombre no son suficientes si no se comprende de qué manera funcionan como técnicas de hominización. Parte de lo que expone Sloterdijk tiene que ver con desmitificar las sensaciones, los mitos y las metáforas como simples y sencillas fantasías. En ese sentido es más valioso un ejercicio fenomenológico de las sensaciones o de los ímpetus, que un trabajo antropológico que se limite a definir qué "es" el hombre. Así, la pregunta por el hombre, por lo que es y ha sido, no puede sino provenir de un sentimiento de ahogo, de inmersión desprotegida en la que su existencia se ve completamente empujada a buscar una salida. La pregunta por el hombre es un salto hacia sí mismo, una búsqueda de su humanidad en el relato, en la posibilidad de gestar una metáfora que haga efectiva su existencia. El hombre es un animal que se promete a sí mismo una salida, un afuera que 
lo empuja más allá de sus propias limitantes y del ahogo que le causan sus propios cuestionamientos vitales. La humanización consiste en ese tránsito en el que las preguntas modifican el suelo existencial para hacer de la extensa llanura del ahogo un bosque de relatos y autobosquejos. El mundo del hombre es el resultado de las promesas que este se ha hecho desde sus afirmaciones y negaciones, así como dice Sloterdijk: "La fuerza en el sujeto aparece en el escenario abierto universal como sufrimiento de la determinación y de la autodeterminación. En esta línea humanización casa a la perfección con autobosquejo y agresión" (Sloterdijk, 2008, p. 38). Quien es hombre vive de manera trágica en el tránsito que lo lleva desde su no-humanidad hasta una salida que lo hace humano desde el relato, la metáfora y la promesa. El salto ontológico consiste en recorrer ese camino que va desde la sensación de extrañeza originaria del hombre hacia la pregunta de cómo habita y traza caminos en el mapa de su mundo. El cuestionamiento del hombre pasa entonces por un análisis profundo de su situación como arrojado en el mundo, como ser desvalido que por medio de relatos ha construido un entorno ficcional, una segunda naturaleza cultural en la que es posible adquirir su estatuto como humano.

La segunda vía del salto debe ser llamada "salto genealógico", porque ella describe las técnicas de hominización y los cambios en las valoraciones del espacio humano como mundo creado a través de prácticas y ejercicios. En esta segunda vía, la cuestión consiste en desarrollar una de las premisas que se han obtenido con la problematización del suelo existencial. A través de Gehlen, Sloterdijk ha demostrado que el hombre es un ser desvalido y deficitario que cumple su humanización bajo una serie de técnicas en las que crea un medio ambiente artificial, una segunda naturaleza de carácter técnico que le resguarda del hostil y violento afuera natural. Aquí se estructura una exploración que diagnostica de qué manera y bajo qué condiciones los hombres aparecen en el mundo como seres capaces de transformar técnicamente su naturaleza primera. Esta segunda vía no será desarrollada en este capítulo, sino en los dos capítulos siguientes.

Por ahora, se hará énfasis únicamente en la primera vía para ir aclarando lo que hemos denominado ontogenealogía, que está contenida en las lecciones que Sloterdijk pronunció en 1988 en la Universidad de Frankfurt, donde se concentró en desarrollar y explicitar en qué consistía una poética del mundo. En esas lecciones es evidente una fuerte influencia del pensamiento de Nietzsche, sobre todo de sus Consideraciones intempestivas, en las que el pensador del martillo hace del presente un objeto de diagnóstico. En particular, la segunda intempestiva, titulada Sobre la utilidad y el perjuicio de la historia para la vida, construye todo un marco de referencia en el que el tema de la historia empieza a inmiscuirse en la reflexión antropológica misma. La historia funciona 
aquí como un relato, como una metáfora que permite al hombre construirse a sí mismo. En ese sentido, y siguiendo las indicaciones de Nietzsche, Sloterdijk muestra que el hombre es un animal poético que necesita de la creación de un suelo metafórico, de una segunda naturaleza, de una historia que le sirva como carga de tradición y que naturalice sus modos de habitar el mundo.

La historia funciona como un relato de humanización en el cual se exaltan ciertas autodeterminaciones de hombres pasados y se estructuran grandes monumentos que tras de sí pueden o no dejar lugar a la creación. La historia produce hombres de diferentes maneras: Nietzsche distingue tres tipos de historia e identifica cómo funcionan para forjar la estructura del presente y el carácter mismo de los individuos. En su diagnóstico, afirma que el hombre puede autorrepresentarse a partir de la "historia monumental", de la "historia anticuaria" y de la "historia crítica". Los hombres creados a partir de la historia monumental necesitan actuar y esforzarse para superar esos eventos del pasado que siempre los sobrepasan, son hombres que viven a la sombra de un pasado mejor y que deciden ser como el arquetipo de hombre que la historia ha creado. Sin embargo, esa historia monumental discrimina acontecimientos y oculta despreciando lo que no le parece lo suficientemente grande. A través de esa historia los hombres tienden a magnificar los hechos y ocultar las prácticas, son hombres de Estado, religión y ciencia para quienes algo nuevo no puede ser concebido gracias a la certeza de lo sido. La creación queda ahogada.

Cuando la consideración monumental del pasado domina sobre las otras maneras de considerar la historia, esto es, la anticuaria y la crítica, sufre el pasado de ese mismo daño: grandes partes de este se olvidan, se desprecian, constituyéndose algo parecido a una corriente gris continua en la que solo los hechos particulares previamente adornados se alzan como archipiélagos aislados (Nietzsche, 2009, p. 340).

En segundo lugar, la historia anticuaria mira el pasado con la nostalgia de que todo tiempo pasado fue mejor. El hombre anticuario necesita venerar y conservar, es un archivero que siente que el presente no tendría vida si no fuese por el espectro de un pasado insuperable; él no actúa en el presente porque ha decidido aferrarse a una vida que está distante, en un tiempo que ya no le pertenece. Conserva los ídolos de barro y prefiere las miradas hacia atrás que el enfoque y la acción en un presente inmediato. 
Por último, Nietzsche identifica un tercer tipo de narración histórica, la historia crítica, donde el pasado es visto para ser juzgado y valorado de acuerdo con la situación que el hombre padece en el presente. "Es menester que el hombre, para poder vivir, tenga la fuerza de destruir y liberarse del pasado, así como que pueda emplear dicha fuerza de vez en cuando" (Nietzsche, 2009, p. 346). En ese sentido, la fuerza de la creación y la actitud histórica resuenan con el modelo propuesto por Sloterdijk de una construcción del mundo a partir de la fuerza creadora del hombre. De este modo, el concepto de poética del mundo, el cual ve en el hombre una potencia que se desenvuelve y despliega desde la creación en la medida que usa el pasado e indaga por las condiciones del mismo, puede ser pensado como una historia crítica en el sentido nietzscheano.

Se trata del intento de darse a posteriori un pasado del que se quiera proceder frente al pasado del que efectivamente se procede, un intento que es siempre peligroso, no solo porque es difícil encontrar un límite a la negación del pasado, sino porque las segundas naturalezas son, en la mayor parte de los casos, más débiles que las primeras (Nietzsche, 2009, p. 347).

El concepto de poética del mundo resuena con la indicación de la construcción a posteriori del pasado, en la medida que construye el mundo desde el presente, explora los límites y el modo de construcción con el fin de dar completa comprensión al ahora. La poética del mundo es una cartografía de aquellas condiciones que hacen posible el mundo humano, una analítica del venir al mundo en la que se responden las preguntas del salto ontológico: qué ha sido y qué es el hombre. El séptuple armazón de las condiciones de posibilidad tratado en Venir al mundo, venir al lenguaje (2006) resuena, tanto con la segunda intempestiva sobre la historia, como con el proyecto de la verdad como metáfora desarrollado en Sobre verdad y mentira en sentido extra-moral.

En la cuarta lección de Venir al mundo, venir al lenguaje puede leerse cómo la problematización antropológica salta y arremete contra la propia singularidad cuando se asumen las preguntas dentro de una racionalidad histórica que intenta responder qué es el hombre, argumentando qué ha sido y cómo ha comenzado:

Si el "hombre" es el animal narrador por antonomasia es porque también es la criatura condenada a comenzar que está obligada a orientarse en el mundo sin poder estar presente en su comienzo "real" como testigo despierto. No está destinado a poder comenzar consigo mismo como un animal privado de lenguaje que 
olfatea la apertura al afuera, sino a hacerse cargo de sí solo desde el momento en que el lenguaje me da a mí mismo. De ahí que tampone el agujero del comienzo con relatos, y comience a enredarse con esos relatos, porque él es la criatura que no dispone de su comienzo (Sloterdijk, 2006, p. 41).

Esa imposibilidad de empezar desde sí mismo con la llegada al mundo es para el hombre parte de su constitución ontológica: el hombre es un ser desvalido, un sujeto ajeno a un comienzo despierto que usa el lenguaje como una técnica de humanización y entrada al mundo. El ser humano rellena el agujero de la falta de palabra con diversos relatos sobre su comienzo, y crea de esta manera una serie de prótesis que abren y configuran un mundo climatizado y técnico. En tanto que el hombre reconozca su carencia de comienzo, empezará a crear formas narrativas de acceder a él; sin embargo, para Sloterdijk estos intentos de comienzo por sí mismo y de empeño regresivo hacia el origen solo tienen justificación si el comienzo es visto como una continuación y no como una serie de discontinuidades novedosas cuyo sustento sea el acto de comenzar por comen$z^{4}{ }^{4}$. De hecho, para Sloterdijk comenzar es en realidad continuar los impulsos de un trabajo narrativo sobre sí mismo, que intenta resolver esas páginas no recordadas en el estadio del nacimiento:

Cuanto más radicalmente tratan los hombres de volver a sus páginas de atrás, más poderosas son las razones que tienen para comenzar de nuevo y más intensa es su preocupación porque algo que tiene un comienzo complicado no termine también convirtiéndose en un mal final (Sloterdijk, 2006, p. 54).

La carencia de un comienzo claro impulsa al hombre a estar configurando continuamente su mundo desde la metáfora y el relato. Los hombres son seres de promesa cuyo ánimo ontológico está inspirado en la narrativa que tapona el vacío del comienzo haciendo cálida la estancia mundana. Sloterdijk hace del problema de la venida al mundo el centro de su reflexión, en la que encuentra una serie de gestos a priori (condiciones de posibilidad), gracias a los cuales el hombre construye el mundo como tal. La poética del mundo aparece en Sloterdijk como una poética del parto en la que el nacimiento es el acontecimiento histórico de estructura ontológica. El lenguaje y la metáfora son

No se trata de un viaje hacia el primer origen, hacia ese primer comienzo que se vuelve fundamento, no es una búsqueda de ursprung, sino de la entstehung. 
técnicas en la mano del hombre que permiten la estructuración del mundo como lugar habitable, como afuera cálido y perfectamente climatizado. Este tipo de técnicas narrativas le permiten reconstruir un mundo histórico que ha sido valorado de diferentes maneras y ofrece la posibilidad de juzgar ese mundo desde un lugar-otro que ha sido creado desde la eventualidad de revalorar el sentido.

Este argumento se cierra entonces diciendo que Sloterdijk se apropia de la tradición de la antropología filosófica de una forma muy particular, al mostrar cómo la pregunta por el hombre funciona como una técnica de hominización. La misma antropología filosófica ha sido un discurso a través del cual el hombre se pregunta por sí mismo, pero no encuentra en ella una respuesta por el comenzar. Solo la pregunta por el venir al mundo, por el entstehung puede servir como técnica que permita al hombre del presente fortalecerse, desplegar sus fuerzas, a la manera de la historia crítica de la que nos hablaba Nietzsche. La antropología filosófica queda convertida, de este modo, en una ontogenealogía, cuyos contornos serán explorados en los dos capítulos siguientes. 
